\title{
SIGNIFICANCE OF CHITOSAN TO IMPROVE THE SUBSTANTIVITY OF REACTIVE DYES
}

\author{
S. A. S. CHATHA', A. I. HUSSAIN ${ }^{1}$, S. ALI $I^{2}$, M. J. SAIF', A. I. MALLHI', M. SAGIR ${ }^{3}$, M. Y. NAZ \\ ${ }^{1}$ Department of Applied Chemistry\& Biochemistry, Government College University, Faisalabad-38000, Pakistan \\ ${ }^{2}$ Department of Chemistry \& Biochemistry, University of Agriculture, Faisalabad-38040, Pakistan \\ ${ }^{3}$ Department of Chemical Engineering, University of Gujrat, Pakistan \\ ${ }^{4}$ Department of Mechanical Engineering, Universiti Tecknologi PETRONAS, 32610 Bandar Seri Iskandar, Malaysia \\ ${ }^{4}$ Department of Physics, University of Agriculture, 38040 Faisalabad, Pakistan
}

\begin{abstract}
Chitosan (polysaccharide) is used for cationization of cotton and to increase the uptake of reactive dye by the cationized cotton. Four different concentration of chitosan $(0.5,1.0,1.5$ and $2.0 \%)$ were applied for 0.5 and $4.0 \%$ shades of C.I. Reactive Red and C.I. Reactive Yellow dye, respectively. Different properties e.g. $\mathrm{K} / \mathrm{S}$ value, washing fastness, light fastness and rubbing fastness of the dyed cotton (untreated and treated with chitosan) were recorded for comparison. The K/S values of chitosan treated fabrics (6.1-13.9 and 18.3-22.8 for both dye shades, respectively) were considerably better than untreated fabric (4.7-5.3 and 16.8-17.0). The results of present study clearly demonstrated that the use of chitosan as an exhausting agent not only reduced the amount of dye for dyeing the cotton fabric but also improved the washing and rubbing fastness properties. The present study further demonstrated that the use of chitosan in textile industry can minimize the dyeing cost, effluent treatment cost and other auxiliary utilization.
\end{abstract}

Keywords- Chitosan, exhausting agent, reactive dyes, washing fastness, light fastness

\section{INTRODUCTION}

The low exhaustion of dye from the dyeing bath is not only economical threat to dyeing process but also have some serious environment concerns due to the toxicity of dye molecules released into water bodies $^{1,2}$.The use of different salts to enhance the exhaustion of dye in the dyeing process is a common practice in the dyeing units of textile industries s.4. $^{3,4}$. The large amount of salts used in textile dyeing can cause pollution of rivers and streams that is a detrimental for aquatic life ${ }^{5}$. As an attempt to reduce the use of salts, a number of researchers have cationized cotton fibers through chemical modifications with the compounds containing cationic groups to enhance the uptake of dyes from dye bath to fibers ${ }^{6-8}$. The majority of the chemicals used for the cationization of cotton are associated with some serious environmental concerns ${ }^{9}$. The textile industry continues to look for eco-friendly processes that can substitute for toxic textile chemicals. In this point of view, chitosan is an excellent candidate for an eco-friendly textile chemical ${ }^{10}$.

Chitosan (Polysaccharide) is a polycationic biopolymer having unique properties such as biodegradability, non-toxicity, antimicrobial activity and poly-cationic nature can be suitable molecule for a number of textile applications ${ }^{11-13}$. Chitosan is the deacetylated derivative of chitin that is the second most abundant polysaccharide found on earth next to cellulose ${ }^{12,13}$.

The applications of chitosan has become the focus of research in multiareas such as pharmaceutical and medical applications, paper production, antimicrobial textiles finishes, fiber formation, wastewater treatment, biotechnology, cosmetics, food processing and agriculture due to its versatile chemical and physical properties, $8,10,12,13$. The application of chitosan in cotton dyeing could reduce the use of dyes and dyes in wastewaters due to the increased dye exhaustion ${ }^{11,14,15}$. Moreover, the use of chitosan treatments in the textile dyeing process can represent a very sound practice due to its environment friendly characteristics. The main objective of the present work was to apply chitosan in different concentrations on cotton fabric and then investigate its effect on the uptake of the dye by the cotton fabric and its impact on the color properties of dyed fabric.

\section{EXPERIMENTAL}

\section{Collection of materials}

Knitted cotton fabric was procured from Jinnah colony, Faisalabad, Pakistan. C.I. Reactive Red dye (Sandalfix Red $\mathrm{C}_{4} \mathrm{BLN}$ 150\%, formula $\mathrm{C}_{31} \mathrm{H}_{20} \mathrm{~N}_{7} \mathrm{O}_{16} \mathrm{~S}_{5} \mathrm{Na}_{4} \mathrm{Cl}$, MW 1033.5), C.I. Reactive Yellow dye (Sandalfix G. Yellow CRL $150 \%$, formula $\mathrm{C}_{28} \mathrm{H}_{20} \mathrm{ClN}_{9} \mathrm{Na}_{4} \mathrm{O}_{16} \mathrm{~S}_{5}$, MW 1026.25), were provided by Sandal Dyestuffs Industries Limited, Faisalabad, Pakistan. Chitosan (off white powder, ash contents $2 \%$, deacetylation $>85 \%$, protein contents $1 \%$ ) was purchased from Sigma-Aldrich (Amherst NY, USA) and used without further purification. All the other chemicals and reagents used in this research were of analytical grade and were purchased from Merck
(Darmstadt, Germany), unless stated otherwise. Application of chitosan on cotton fabric

Before dyeing, the grey fabric was bleached using $50 \% \mathrm{H}_{2} \mathrm{O}_{2}(20 \mathrm{~g} / \mathrm{L})$ and $50 \% \mathrm{NaOH}(15 \mathrm{~g} / \mathrm{L})$ for 30 minutes at $50^{\circ} \mathrm{C}$. The bleached cotton fabric was neutralized by rinsing with water. The fabric was treated with different concentrations $(0.5,1.0,1.5$ and $2.0 \%$ on weight of fabric) of chitosan (solution prepared in acetic acid) to investigate its effect as an exhausting agent.

Dyeing of treated and controlled fabric samples

Treated and controlled (untreated) fabric samples were dyed with C.I. Reactive Red ( $\mathrm{C}_{4} \mathrm{BLN} 150 \%$ ) dye and C.I. Reactive Yellow (CRL 150\%) dye separately in 0.5 and $4 \%$ shade strength, following the previously established method ${ }^{16}$ with some modifications. Fabric to liquid solution ratio was kept at 1:15 and dyeing was carried out using exhaust dyeing machine at $45^{\circ} \mathrm{C}$ for 15 min, followed by at $65^{\circ} \mathrm{C}$ for $60 \mathrm{~min}$. The dyed fabric was rinsed with tap water thoroughly and labeled after air drying.

\section{Measurement of color strength of dyed fabric}

The color yield K/S values of treated and controlled dyed cotton fabric samples at the maximum light absorption wavelength were measured under D65/10 illuminant by using Spectraflash Spectrophotometer F650 using a measuring area with a diameter of $9 \mathrm{~mm}$, at Sandal Dyestuffs Quality Control Laboratory, Faisalabad, Pakistan. The colorimeter was calibrated before testing against a standard white board. Samples were measured three times in each of five sites, and the average of the measurements was recorded as the $\mathrm{K} / \mathrm{Svalue}^{2}$.

\section{Determination of color fastness properties}

\section{Determination of washing fastness}

The washing fastness of treated and control fabrics were measured according to test method established by American Association of Textile Chemists and Colorists ${ }^{17}$ using an ATLAS Launder-Ometer. One cycle of laundering by this method is considered equivalent to five home machine launderings at medium or warm setting at the temperature range of $38 \pm 3^{\circ} \mathrm{C}$. The treated fabrics $(5 \times$ $15 \mathrm{~cm}$ ) were subject to laundering with reference detergent WOB. At the end fabrics were rinsed with warm water using a home laundering machine and airdried. The color fastnesses were assessed and sorted into five grades, marked $1,2,3,4$, and 5 , according to ISO/BS standard gray card. Grade 1 means that the color change is evident and grade 5 is not noticed. All experiments were carried out at least in triplicate.

\section{Determination of light fastness}

The light fastness was measured by using digital light fastness tester (Paradise Laboratory Instrument and Company, Faisalabad, Pakistan) and Xenon arc lamp as a light source as an established method ${ }^{18}$.

\section{Determination of rubbing fastness}

The rubbing fastness was measured by crock-meter according to the standard method ${ }^{18}$. A colored test specimen was rubbed with the white crock test cloth (wet and dry) under controlled conditions. Similar to washing fastness, the color fastnesses to rubbing were also assessed and sorted into five grades, marked 1, 2, 3, 4, and 5, according to ISO/BS standard gray card. 
Grade 1 means that the color change is evident and grade 5 is not noticed. All experiments were carried out at least in triplicate.

\section{RESULTS AND DISCUSSION}

\section{Effect of chitosan treatment on color strength of dyed fabric}

The color strength (K/S values) of chitosan treated and control (untreated) fabric samples are given in Table 1. It was observed that the cotton fabric treated with different concentration of chitosan showed the better performance in terms of dye uptake from dye bath, indicated by the higher $\mathrm{K} / \mathrm{S}$ values of the cotton fabric treated with chitosan as compared to untreated fabric. Chitosan treatment increased the dye uptake of cotton fabric in a concentration dependent manner. However, a decline was observed in exhaustion beyond the $2 \%$ concentration of chitosan treatment for both investigated reactive dyes. The higher color yield in treated cotton might be attributed to the formation of ionic bonding between the cationic groups of chitosan and anioic functional groups of dye molecules. The chitosan treatment resulted in cationization of cellulosic fabric surface and thus provides a platform for the maximum exhaustion of dye bath. The surface cationization of cotton can enhance the dye up take due to ionic interaction between cationic group of chitosan and anionic group of dye ${ }^{14}$. In support to our present finding, the most of the researchers have a very common claim that due to its unique molecular structure, chitosan has an extremely high affinity for many classes of dyes ${ }^{12}$. Similarly, the results of present research were found parallel to the previously published data using the similar criterion with different dyestuff, shade strengths and dye boosters ${ }^{9,12,14}$. The reason for the decline of color yield at high chitosan concentration treatment can be explained on the ground that when concentration of chitosan is increased up to $1.5 \%$, there are more spaces and functional groups available for the dye molecules to get attached to the cotton fabric but by further increasing the chitosan concentration, the fabric is more covered up by chitosan molecules hence bonding of dye molecules with cotton functional groups decreases. Previously published data seem to revealing the fact that although dye uptake increased as chitosan treatment concentration increased, fabrics got stiffer at higher chitosan treatment concentration. Chitosan, a biodegradable polymer distributed into the environment in a dispersed manner is being used in textile dyeing process not only to increase the uptake of dyes by the fabric; it also represents an environmentally sound practice ${ }^{12}$.

Table 1: K/S values of fabric samples (control and chitosan treated) dyed with $0.5 \%$ and $4.0 \%$ of reactive red and reactive yellow.

\begin{tabular}{|c|c|c|c|c|c|c|}
\hline \multirow{2}{*}{ Dye } & \multirow{2}{*}{ Dye shade (\%) } & Control fabric sample & \multicolumn{3}{|c|}{ Fabric treated with different concentrations of chitosan } \\
\cline { 3 - 7 } & & & $\mathbf{0 . 5 \%}$ & $\mathbf{1 \%}$ & $\mathbf{1 . 5 \%}$ & $\mathbf{2 \%}$ \\
\hline \multirow{2}{*}{$\begin{array}{c}\text { C.I. Reactive Red } \\
\left(\text { C }_{4} \text { BLN 150\%) }\right.\end{array}$} & 0.5 & 4.7 & 6.1 & 7.2 & 8.4 & 6.0 \\
\hline \multirow{2}{*}{$\begin{array}{c}\text { C.I. Reactive Yellow } \\
\text { (CRL 150\%) }\end{array}$} & 4.0 & 17.0 & 19.4 & 20.5 & 22.6 & 22.1 \\
\cline { 2 - 7 } & 0.5 & 5.3 & 9.7 & 10.1 & 13.9 & 11.2 \\
\hline
\end{tabular}

Table 2: Color fastness tests of control and chitosan treated samples dyed with C.I. Reactive Red (C4BLN 150\%).

\begin{tabular}{|c|c|c|c|c|c|c|}
\hline \multirow{2}{*}{ Properties } & \multirow{2}{*}{ Dye shade (\%) } & \multirow{2}{*}{ Control fabric sample } & \multicolumn{4}{|c|}{ Fabric treated with difference concentrations of chitosan } \\
\hline & & & $0.5 \%$ & $1 \%$ & $1.5 \%$ & $2 \%$ \\
\hline \multirow{2}{*}{$\begin{array}{l}\text { Washing } \\
\text { Fastness }\end{array}$} & 0.5 & 4 & 4.5 & 4.5 & 4.5 & 4 \\
\hline & 4.0 & 4 & 4.5 & 4.5 & 4.5 & 4 \\
\hline \multirow{2}{*}{ Dry Rubbing } & 0.5 & 4 & 4.5 & 4.5 & 4.5 & 4 \\
\hline & 4.0 & 4 & 4.5 & 4.5 & 4.5 & 3.5 \\
\hline \multirow{2}{*}{ Wet Rubbing } & 0.5 & 3.5 & 4.0 & 4.0 & 4.0 & 3.0 \\
\hline & 4.0 & 3.0 & 3.5 & 3.5 & 3.5 & 3 \\
\hline \multirow{2}{*}{ Light Fastness } & 0.5 & 5 & 5 & 5 & 5 & 5 \\
\hline & 4.0 & 5 & 5 & 5 & 5 & 5 \\
\hline
\end{tabular}

Table 3: Color fastness tests of control and chitosan treated samples dyed with C.I. Reactive Yellow (CRL 150\%).

\begin{tabular}{|c|c|c|c|c|c|c|}
\hline \multirow{2}{*}{ Properties } & Dye shade (\%) & \multirow{2}{*}{$\begin{array}{c}\text { Control fabric } \\
\text { sample }\end{array}$} & \multicolumn{4}{|c|}{ Fabric treated with difference concentrations of chitosan } \\
\cline { 4 - 7 } & & $\mathbf{0 . 5}$ & $\mathbf{1 \%}$ & $\mathbf{1 . 5 \%}$ & $\mathbf{2 \%}$ \\
\hline \multirow{2}{*}{$\begin{array}{c}\text { Fashing } \\
\text { Fastness }\end{array}$} & 0.5 & 4 & 4.5 & 4.5 & 4.5 & 4.5 \\
\cline { 2 - 7 } & 4.0 & 4 & 4.5 & 4.5 & 4.5 & 4.5 \\
\hline \multirow{2}{*}{ Dry Rubbing } & 0.5 & 4 & 4.5 & 4.5 & 4.5 & 4.5 \\
\cline { 2 - 7 } & 4.0 & 4 & 4.5 & 4.5 & 4.5 & 4.0 \\
\hline \multirow{2}{*}{ Wet Rubbing } & 0.5 & 3.5 & 4.0 & 4.0 & 4.0 & 3.5 \\
\cline { 2 - 7 } & 4.0 & 3.0 & 3.5 & 3.5 & 3.5 & 3 \\
\hline
\end{tabular}

Effect of chitosan treatment on color fastness to washing

Data regarding color fastness properties of chitosan treated and untreated cotton fabric dyed with C.I. Reactive Red and C.I. Reactive Yellow dyes have been presented in Table 2 and Table 3, respectively. All the chitosan treated cotton fabric samples were found better in color fastness to washing as compared to control fabric samples, however, the performance of chitosan treatment for the improvement of washing fastness property of dyed fabric for both the dyes (C.I. Reactive Red and C.I. Reactive Yellow dyes) was almost comparable. The better results in case of chitosan treatment over control experiment can be explained on the ground that the cationization of cellulosic fabric surface by the application of chitosan, can develop strong bonding due to ionic interaction between cationic 
group of chitosan and anionic group of dye that furnish the better color fastness properties to dyed fabric. Zhang and Zhang ${ }^{19}$ investigated the improving the dyeing properties of hemp fabric using chitosan treatment which clearly in line with the finding of our present investigation regarding the parameter color fastness to washing. Literature provides the sound evidences that more the available spaces on cellulosic fabric surface, provide the more reactive sites and thus better attachments/bonding between fabric surface and dye molecules and better color fastness properties ${ }^{9}$. The washing fastness of dyed cotton fabric followed by the application of chitosan at concentration $2 \%$ did not showed any improvement as compared to control samples that can be explained on the ground that at this high concentration of chitosan the fabric is more covered up by chitosan molecules hence bonding of dye molecules with cotton functional groups decreases, resulting the poor washing fastness.

Effect of chitosan treatment on color fastness to light

The data regarding color fastness to light for the chitosan treated and untreated cotton fabric has been presented in Table 2 and Table 3. It was observed that all the fabric samples, untreated and treated with different concentrations of chitosan have equally good light fastness property. In light fastness test, there was no any relation of light to the dye and fiber bond so that's why light fastness test does not have any effect on fabric. Our results showed that the light fastness of chitosan treated cotton samples were not or slightly decreased while we expected higher light fastness for them due to their deeper depths ${ }^{9}$.The moisture absorption of chitosan treated cotton fabrics were studied on cotton and it was claimed that the wetting ability of the substrates was slightly enhanced ${ }^{16,20}$. The light fastness of textile materials was affected by the effective moisture, significantly. So, any depletion of light fastness of treated samples can originate from this type of change ${ }^{6}$.

\section{Effect of chitosan treatment on color fastness to rubbing}

Table 2 and Table 3 show that the data regarding color fastness to wet and dry rubbing for the cotton fabric dyed with C.I. Reactive Red and C.I. Reactive Yellow dyes, respectively. It was observed that untreated samples showed good fastness to rubbing whereas, the samples treated with different concentrations of chitosan presented poor fastness to rubbing. However, the dyeing properties regarding the parameter color fastness to washing of hemp fabric using chitosan treatment investigated by Zhang and Zhang ${ }^{19}$ are in line with the finding of our present investigation. This difference in the color fastness to wet and dry rubbing of treated and untreated cotton fabric dyed with both of reactive dyes on the ground that for the chitosan pretreated fabric samples, greater amount of dye molecules present on the surface and during the course of rubbing a large amount of dye molecules present on the surface were removed off and that's why treated samples showed poor fastness to rubbing as compared to control samples. Comparatively dry rubbing fastness was much better than wet rubbing fastness. In case of wet rubbing solvent (water) furnishes the basis of dissolution of dye molecules and hence the wet rubbing test gives poor results ${ }^{21}$.

Overall, it was investigated that the application of acidic solution of chitosan on cotton fabric before dyeing can boost up the exhaustion of dye bath as well as improves the substantively of reactive dyes. The effect, however, was decreased by increasing the chitosan concentration from 1.5 to $2.0 \%$. The recipe with $1.5 \%$ chitosan is still cost effective and applicable for industrial application. The optimal concentration of chitosan in our findings was $1.5 \%$ that is in line with the findings of Yen and $\mathrm{Chen}^{22}$ who reported $1.6 \%$ as optimal chitosan concentration for the similar investigation.

\section{CONCLUSION}

The majority of the chemicals used for the cationization of cotton are not safe from environmental view point. The use of chitosan, a polycationic biopolymer with unique properties (biodegradable and non-toxic) makes it suitable for a number of textile applications for the improvement of substantively of reactive dyes. In the present study the cotton fabric pretreated with chitosan $(1.5 \%$ owf) gave the higher color yield along with the significant improvement in the washing fastness. On the basis of the findings of present study it is reasonable to say that chitosan treatment to the cotton fabric before dyeing can reduce the amount of reactive dye to be used in the dyeing units of textile industries and thus can reduce the production cost as well as environmental concerns.

\section{REFERENCES}

1.- M. Asgher, H.N. Bhatti, M. Ashraf,R.L. Legge,: Review paper. Biodegrad.2008,19,771.

2.- S.A.S. Chatha, M. Asgher, S. Ali, A.I. Hussain,. Carbo.Polym., 2012,87,1476-1481.

3.- P.P. Karnik,. Ph.D. Thesis, North Carolina State University, U.S.A.2002.

4.- S.A.S. Chatha,. Thesis, University of Agriculture, Faisalabad, Pakistan, 2011.

5.- S.A.S. Chatha, M. Asgher, S. Ali, H.N. Bhatti,. Text. Res. J.,2011,8117621771.

6.- S. Houshyar,. M.Sc. Thesis, Isfahan University of Technology, Iran, 1999.

7.- A. Hashem,R.M. El-Shishtawy,. Adsorp. Sci. Tech.,2001,19,197-210.

8.- M. Montazer, R.M.A. Malek, A. Rahimi,. Fibers Polym.,2007,8,608-612.

9.- S. Houshyar, S.H. Amirshahi,. Iranian Polym. J., 2002,5,295-301.

10.- S.H. Lim, S.M. Hudson,. Carbo. Polym.2004,56, 227-234.

11.- J.M. Canal， C. Rodriquenz, G. Caballero,R.M. Julia,.Dyes Pigm.1998,183,16-24.

12.- N.V. Majeti, R. Kumar,. Reactive Funct.Polym.,2000,461-27.

13.- S.H. Lim,S.M. Hudson,. Carbo. Res.,2004,339,313-319.

14.- D. Gupta, A. Haile,. Carbo. Polym.,2007,69, 164-171.

15.- M. Kong, X.G. Chen, K. Xing, H.J. Park,. Inter. J. Food Microbiol.,2010,144, 51-63.

16.- C.I. Pearce, J.R. Lloyb, J.T. Guthrie,. Dyes Pigm., 2003,58, 179-196.

17.- American Association of Textile Chemists and Colorists, Vol. 75, Technical Manual, NC: Research Triangle Park, 2000.

18.- American Society for Testing and Materials, Vol. 11.05, Annual Book of ASTM Standards, PA: West Conshohocken, 2001.

19.- H. Zhang, L.M. Zhang. J. Text. Instit., 2010, 101, 849-857.

20.- M.R. Julia, E. Pascual, P. Erra,. J. Soc. Dyers Col., 2000,116, 62-68.

21.- R.D. Mehta, R. Combs,. Dyestuff Reporter., 1998,110, 43-45.

22.- Yen Ming-Shien, Chen Chien-Wen,. African J. Biotechnol., 2011,10, 1421-1427. 